\title{
Nickel/Zinc Ratio and Lanthanum Substitution Effect on Structural and Magnetic Properties of Nickel Zinc Ferrites
}

\author{
V. JANČÁRIK*, M. ŠOKA, M. UŠÁKOVÁ AND R. HARŤANSKÝ \\ Institute of Electrical Engineering, Faculty of Electrical Engineering and Information Technology, \\ Slovak University of Technology in Bratislava, Ilkovičova 3, 81219 Bratislava
}

\begin{abstract}
Improvement of NiZn ferrites properties by means on $\mathrm{Ni} / \mathrm{Zn}$ content ratio modification and by partial substitution of $\mathrm{Fe}^{3+}$ ions by $\mathrm{La}^{3+}$ ions is presented. $\mathrm{Ni}_{x} \mathrm{Zn}_{1-x} \mathrm{Fe}_{2} \mathrm{O}_{4}$ and $\mathrm{Ni}_{x} \mathrm{Zn}_{1-x} \mathrm{La}_{0.02} \mathrm{Fe}_{1.98} \mathrm{O}_{4}$ samples of small particles were prepared by self-propagated combustion method. X-ray spectroscopy was used for structural analysis, temperature dependence of magnetic susceptibility was used for evaluation of chemical and phase composition. Analysis showed that pure spinel structure without secondary phase caused by La ions for all values of $\mathrm{Ni} / \mathrm{Zn}$ content was present. Noticeable growth of the magnetic susceptibility at room temperature was observed with rising of $\mathrm{Zn}^{2+}$ ions content.
\end{abstract}

DOI: 10.12693/APhysPolA.131.693

PACS/topics: 75.50.Gg, 75.30.Cr, 61.05.C-

\section{Introduction}

Nowadays, attention is still focused on soft magnetic spinel ferrites. They are important and extensively used in several applications due to their good magnetic parameters, high resistivity together with relatively cheap production. There are several approaches to improve their parameters by modification of preparation procedure as well as by definition of an optimal chemical composition. Substitution of $\mathrm{Fe}^{3+}$ ions by rare-earth ions is one of them [1]. Due to chemical composition changes, magneto-crystalline anisotropy and therefore magnetic properties (e.g. resistivity, power losses) of ferrites are influenced [2]. Beside other rare-earth ions, influence of $\mathrm{La}^{3+}$ substitution on ferrite properties has been investigated [3, 4], $\mathrm{Ni}_{0.5} \mathrm{Zn}_{0.5} \mathrm{La}_{y} \mathrm{Fe}_{2-y} \mathrm{O}_{4}$ (fixed $\mathrm{Ni} / \mathrm{Zn}$ ratio), where $y=0-0.3$ ferrite composition was deeply analyzed [5].

The aim of presented work is to study the effect $\mathrm{Ni}^{2+} / \mathrm{Zn}^{2+}$ ratio as well as the influence of partial substitution of $\mathrm{Fe}^{3+}$ ions by $\mathrm{La}^{3+}$ ions on structural and magnetic parameters of ferrites at various values of $\mathrm{Ni}^{2+} / \mathrm{Zn}^{2+}$ ratio.

Several procedures of NiZn ferrite preparation are used yielding different particle size and morphology, and therefore the anisotropy, as ceramic technique [6], nitratecitrate autocombustion method [7], high-energy ball milling [8] and sol-gel technique [9]. Most magnetic parameters are influenced by the particles anisotropy and size. $\mathrm{X}$-ray spectroscopy was used for structural analysis, temperature dependence of magnetic susceptibility was used for evaluation of chemical and phase composition.

\section{Specimen preparation and experiment}

The ferrite powders were prepared by means of glycine-nitrate-acetate autocombustion synthesis. An

*corresponding author; e-mail: vladimir.jancarik@stuba.sk advantage of this synthesis is the wet process of preparation allowing mixing of raw soluble salts in solution on the atomic scale. Thus, better homogeneity of prepared samples is achieved. The ferrite samples with chemical composition $\mathrm{Ni}_{x} \mathrm{Zn}_{1-x} \mathrm{Fe}_{2} \mathrm{O}_{4}$ and $\mathrm{Ni}_{x} \mathrm{Zn}_{1-x} \mathrm{La}_{0.02} \mathrm{Fe}_{1.98} \mathrm{O}_{4}(x=0.3,0.36,0.42,0.5,0.7$, and 1.0) were synthesized from raw salts of analytical grade purity. The nickel nitrate $\mathrm{Ni}\left(\mathrm{NO}_{3}\right)_{2} \cdot 6 \mathrm{H}_{2} \mathrm{O}$, zinc acetate $\mathrm{Zn}\left(\mathrm{CH}_{3} \mathrm{COO}\right)_{2} \cdot 2 \mathrm{H}_{2} \mathrm{O}$, lanthanum nitrate $\mathrm{La}\left(\mathrm{NO}_{3}\right)_{3}$ and iron nitrate $\mathrm{Fe}\left(\mathrm{NO}_{3}\right)_{3} \cdot 9 \mathrm{H}_{2} \mathrm{O}$, as well as glycine $\mathrm{NH}_{2} \mathrm{CH}_{2} \mathrm{COOH}$ acting as the organic precursor in required stoichiometric amount were solved in deionized water. Raw solutions were mixed and heated until the gel consistence was reached. Further, the gel was consecutively heated until the self-propagating combustion process started. Obtained fluffy powder was sintered in the kanthal furnace at the temperature of $850^{\circ} \mathrm{C}$ for $6 \mathrm{~h}$. Prepared ferrite powder samples were analysed by measurement of temperature dependences of magnetic susceptibility. The NiZnLa ferrite structure was investigated and analysed by XRD (Co $K_{\alpha}$ radiation, $\lambda=0.179020 \mathrm{~nm}$ ).

Magnetic susceptibility temperature dependences were measured by an $\mathrm{AC}$ bridge method at magnetic field intensity $760 \mathrm{~A} / \mathrm{m}[10]$. It represents and effective way of indicating phase composition and purity of powder ferrite samples. The $\chi(T)$ dependence is very sensitive to chemical and phase composition of ferrite. Compared with other method as SEM microscopy or XRD, it gives no such detailed information, but it is relatively cheap and quick.

\section{Results and discussion}

Structure of La-substituted NiZn ferrite was characterized by XRD for various NiZn ratio. The phase analysis confirmed single-phase cubic spinel structure for all the prepared ferrite samples. The presence of second phase $\mathrm{LaFeO}_{3}$ was not found since the amount of La ions $(x=0.02)$ was very small. It appears at higher La ion content $(x=0.025)$, besides major spinel struc- 
ture also the minor orthorhombic structure of the $\mathrm{LaFeO}_{3}$ appears [11].

XRD patterns of $\mathrm{Ni}_{x} \mathrm{Zn}_{1-x} \mathrm{La}_{0.02} \mathrm{Fe}_{1.98} \mathrm{O}_{4}$ (Fig. 1) show a small drift of the peak due to increase of $\mathrm{Ni}^{2+}$ concentration in the ferrite composition. This fact was confirmed by structural results, the value of the lattice parameter $a$ slightly decreased with growing content of $\mathrm{Ni}^{2+}$; for the composition $\mathrm{Ni}_{0.3} \mathrm{Zn}_{0.7} \mathrm{La}_{0.02} \mathrm{Fe}_{1.98} \mathrm{O}_{4}(x=0.3)$ with the lowest $\mathrm{Ni}$ contents achieved the higher value $(a=8.41868 \AA)$ and for the maximal amount of $\mathrm{Ni}$ $\left(x=1\right.$, the composition $\mathrm{NiLa}_{0.02} \mathrm{Fe}_{1.98} \mathrm{O}_{4}$, without $\mathrm{Zn}^{2+}$ ions in structure) the value of lattice parameter was the lowest $(a=8.3419 \AA)$.
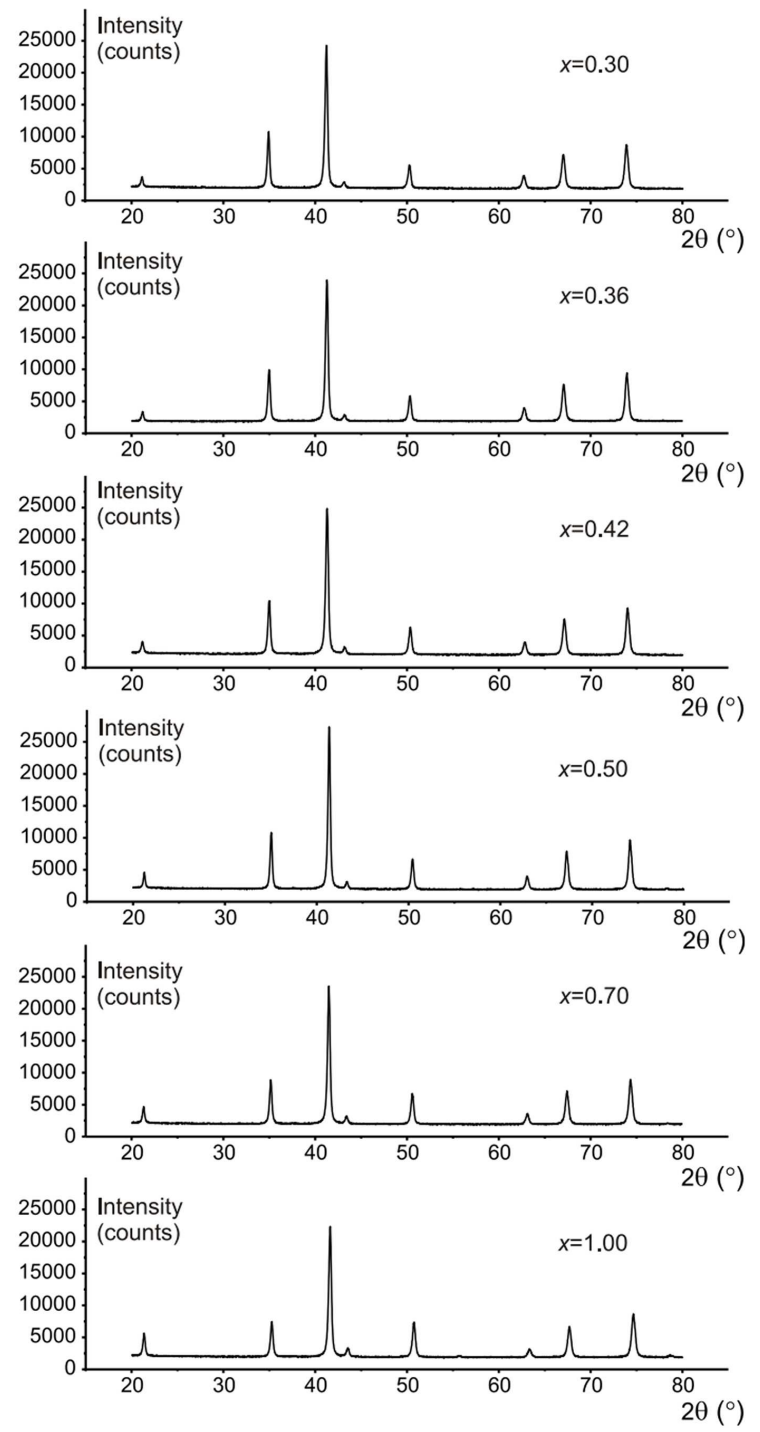

Fig. 1. XRD patterns of $\mathrm{Ni}_{x} \mathrm{Zn}_{1-x} \mathrm{La}_{0.02} \mathrm{Fe}_{1.98} \mathrm{O}_{4}$.

The decrease of the values of lattice parameter $a$ is caused by increasing concentration of $\mathrm{Ni}^{2+}$ ions with the ionic radius of $0.69 \AA$, which is slightly lower than that of $\mathrm{Zn}^{2+}(0.74 \AA)$. The dependence of lattice parameters on the Ni contents in NiZnLa ferrite samples is plotted in Fig. 2.

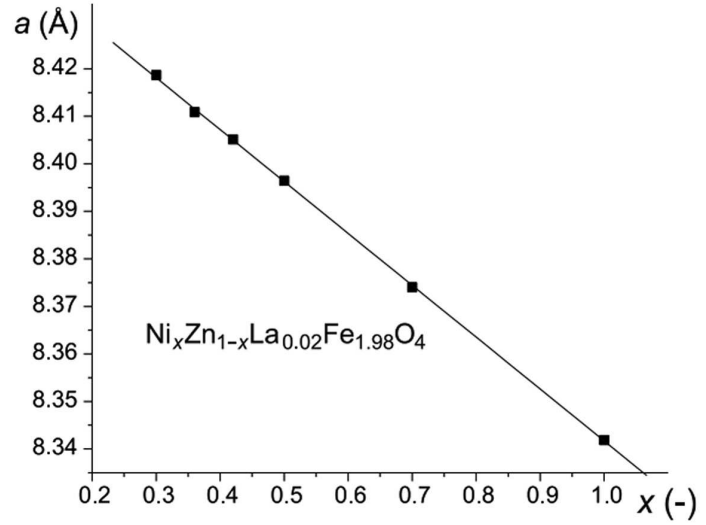

Fig. 2. Dependence of lattice parameter $a$ on the Ni content $x$.

Temperature dependence of magnetic susceptibility was taken both on pure NiZn ferrite as well as on Lasubstituted samples. Dependences without any partial drops indicating presence of secondary phases were found on all samples; excessive Hopkinson peak reveals smallsized ferrite particles [10] (Fig. 3). Such result is in agreement with the self-combustion preparation method.

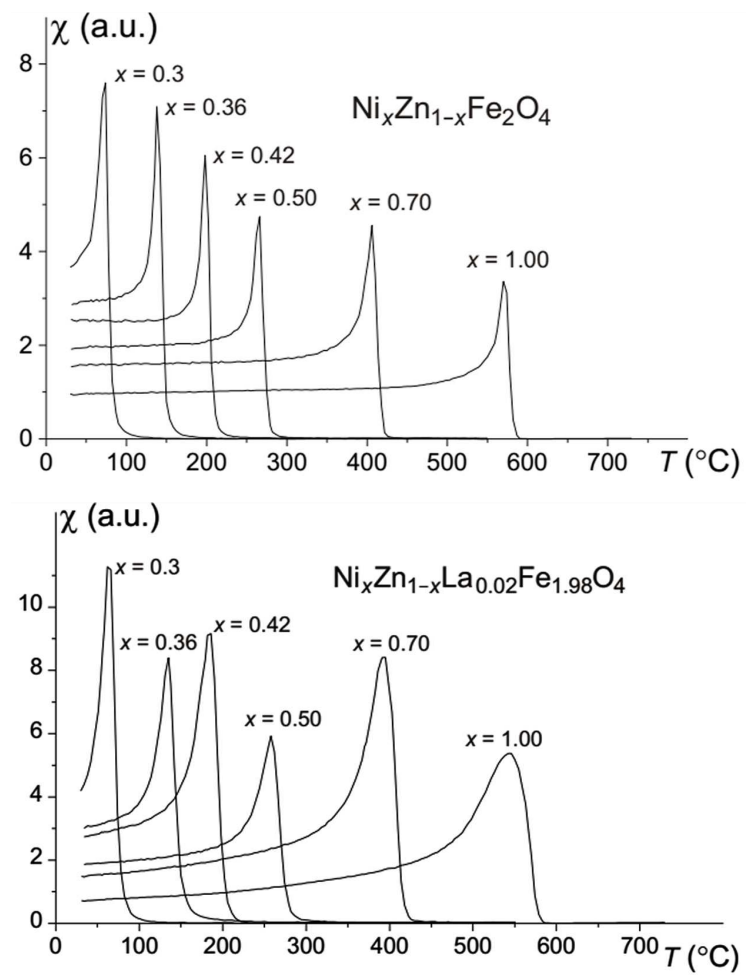

Fig. 3. (top) Temperature dependence of magnetic susceptibility of NiZn ferrite. (bottom) Temperature dependence of magnetic susceptibility of La-substituted NiZn ferrite.

The Curie temperature $T_{\mathrm{C}}$ was evaluated of both pure and La substituted NiZn ferrite samples for all values of $\mathrm{Ni}$ content $x$. It was determined numerically by a point of inflexion on Hopkinson's peak falling edge. The re- 
sults, shown in Table I, reveal increase of $T_{\mathrm{C}}$, with the addition of $\mathrm{Ni}^{2+}$ ions, and slight decrease of $T_{\mathrm{C}}$, with the addition of $\mathrm{La}^{3+}$ ions. Both phenomena can be attributed to the variation of the $\mathrm{Fe}-\mathrm{Fe}$ interaction number. In the first case, enter of $\mathrm{Zn}^{2+}$ ions into the A sites causes replacement of corresponding amount of $\mathrm{Fe}^{3+}$ ions from $\mathrm{A}$ to $\mathrm{B}$ sites, and in the second case, enter of $\mathrm{La}^{3+}$ ions into the $\mathrm{B}$ sites causes decrement of corresponding amount of $\mathrm{Fe}^{3+}$ ions in $\mathrm{B}$ sites and its paramagnetic character may violate coupling between magnetic ions. All described processes result in variation of $\mathrm{A}-\mathrm{B}$ exchange interactions and affect the value of the $T_{\mathrm{C}}[12]$.

TABLE I

Curie temperature of pure and La-substituted NiZn ferrite on Ni content $x$.

\begin{tabular}{c|c|c}
\hline \hline \multirow{2}{*}{$x$} & \multicolumn{2}{|c}{$T_{\mathrm{C}}\left[{ }^{\circ} \mathrm{C}\right]$} \\
\cline { 2 - 3 } & $\mathrm{Ni}_{x} \mathrm{Zn}_{1-x} \mathrm{Fe}_{2} \mathrm{O}_{4}$ & $\mathrm{Ni}_{x} \mathrm{Zn}_{1-x} \mathrm{La}_{0.02} \mathrm{Fe}_{1.98} \mathrm{O}_{4}$ \\
\hline 0.3 & 77.6 & 71.1 \\
0.36 & 145.2 & 141.7 \\
0.42 & 204.2 & 193.8 \\
0.5 & 271.3 & 268 \\
0.7 & 412.7 & 407.8
\end{tabular}

In Fig. 4, there are values of magnetic susceptibility at room temperature. The magnetic susceptibility values of pure NiZn ferrite powders are declining with rising of $x$ and change only a slightly with La-substitution at low $\mathrm{Ni}$ content. It is in accordance with noticed an increase of coercive field [13] associated with growth of the demagnetizing field, and with the magnetocrystalline anisotropy changes, related to the strong spin-orbit coupling of rareearth ions. In addition, we can conclude from these dependences that $\mathrm{Fe}-\mathrm{Fe}$ interaction dominates also in the substituted ferrites regardless on $\mathrm{Ni}$ content [14].

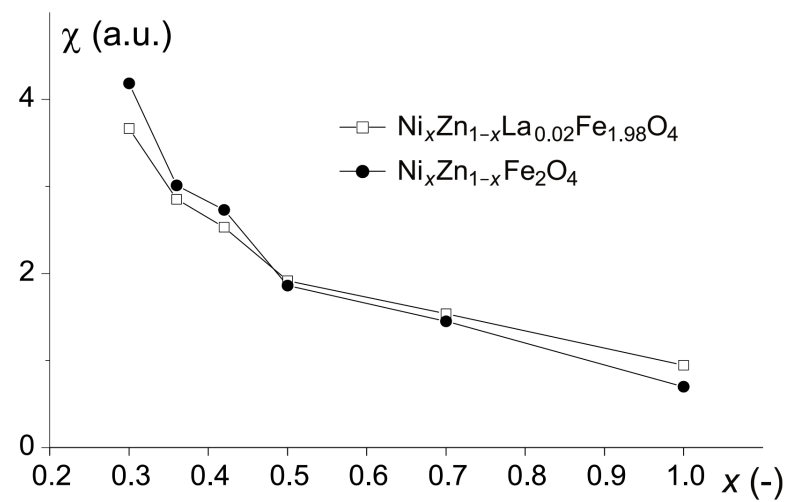

Fig. 4. Dependence of magnetic susceptibility of pure and La-substituted NiZn ferrite on $\mathrm{Ni}$ content $x$ at room temperature.

\section{Conclusions}

La-substituted ferrite samples were prepared with fixed substituent content and of various $\mathrm{Ni} / \mathrm{Zn}$ content. Xray diffraction analysis shows the pure spinel structure without secondary phase caused by La ions for all values of $\mathrm{Ni} / \mathrm{Zn}$ content. It is proved by the temperature dependences of magnetic susceptibility without multiple drops indicating presence of secondary phases. Strong Hopkinson's peak reveals small particle size typical for ferrites prepared by auto-combustion technology. The Curie temperature of pure NiZn ferrite increase with the addition of $\mathrm{Ni}^{2+}$ ions, and slight decrease with the addition of $\mathrm{La}^{3+}$ ions in substituted NiZn ferrite. Moreover, noticeable growth of the magnetic susceptibility at room temperature was observed with rising of $\mathrm{Zn}^{2+}$ ions content.

\section{Acknowledgments}

This work was supported by the Slovak Research and Development Agency under the contracts No. APVV140076, APVV-15-0257 and by the Scientific Grant Agency of the Ministry of Education, Science, Research and Sport of the Slovak Republic, No. VG 1/0571/15. We also thank to E. Dobročka (SAS Bratislava) for help with $\mathrm{XRD}$ analysis.

\section{References}

[1] S.E. Jacobo, S. Duhalde, H.R. Bertorello, J. Magn. Magn. Mater. 272-276, 2253 (2004).

[2] Y.C. Yang, L.S. Kong, S.H. Sun, D.M. Gu, B.P. Cheng, J. Appl. Phys. 63, 3702 (1988).

[3] M.A. Gabal, A.M. Asiri, Y.M. AlAngari, Ceram. Int. 37, 2625 (2011).

[4] Y. Liu, S. Wei, B. Xu, Y. Wang, H. Tian, H. Tong, J. Magn. Magn. Mater. 349, 57 (2014).

[5] X. Wu, W. Wu, L. Qin, K. Wang, S. Ou, K. Zhou, Y. Fan, J. Magn. Magn. Mater. 379, 232 (2015).

[6] S.E. Shirsath, S.M. Patange, R.H. Kadam, M.L. Mane, K.M. Jadhav, J. Mol. Struct. 1024, 77 (2012).

[7] P.K. Roy, B.B. Nayak, J. Bera, J. Magn. Magn. Mater. 320, 1128 (2008).

[8] S. Gao, S. Song, Q. Song, J. Mater. Sci. Chem. Eng. 3, 50 (2015).

[9] N. Chen, M. Gu, Open J. Met. 2, 37 (2012).

[10] V. Jančárik, E. Ušák, J. Electr. Eng. 50, 63 (1999).

[11] P.K. Roy, J. Bera, Mater. Res. Bull. 42, 77 (2007).

[12] G. Aravind, A. Gaffoor, D. Ravinder, V. Nathanial, Adv. Mater. Letters 6, 179 (2015).

[13] A. Verma, T.C. Goel, R.G. Mendiratta, P. Kishan, J. Magn. Magn. Mater. 208, 13 (2000).

[14] N. Rezlescu, E. Rezlescu, Solid State Commun. 88, 139 (1993). 